\begin{tabular}{c}
\hline KeMAS 16 (1) (2020)71-80 \\
Jttp://journal.unnes.ac.id/nju/index.php/kemas
\end{tabular}

\title{
Collaboration Network Model of HIV/AIDS Prevention and Control: Case Study in Subang District, Indonesia
}

\author{
Sam’un Jaja Raharja ${ }^{\bowtie}$, Dede Akhmad \\ Faculty of Social and Political Sciences, Universitas Padjadjaran, Indonesia
}

\begin{tabular}{l} 
Article Info \\
\hline Article History: \\
Submitted October 2019 \\
Accepted April 2020 \\
Published July 2020 \\
\hline Keywords: \\
Collaboration, HIV/ \\
AIDS, networks model \\
\hline DOI \\
https://doi.org/10.15294/ \\
kemas.v16il.21531
\end{tabular}

\begin{abstract}
This study was conducted due to the increasing trend of people living with Human immunodeficiency virus infection and acquired immune deficiency syndrome (HIV/AIDS) (HIV/AIDS) in Subang Regency, West Java Province. This phenomenon was marked by high population mobility. Thus, this study aims to analyze the network model for HIV/ AIDS prevention and control in Subang Regency. In this study, a networking approach by collaboration was adopted using six dimensions, namely, governance, administration, organizational autonomy, mutuality, norms and leadership. A qualitative approach is applied to explain a dataset which was a collection of observation and in - depth interview and supported by secondary data from relevant informants who are involved in preventing and reducing HIV/AIDS in Subang Regency. These informants were the actors who represent government agents and non-government organizations. Result showed that all dimensions of collaboration occur on an iterative, cyclical and dynamic process. However, on a practical approach, this model is implemented on a linear and causality basis and can explain a system towards problem-solving and new values forming.
\end{abstract}

\section{Introduction}

For more than 3 decades, HIV/AIDS prevention and control has been implemented in Indonesia with various dynamics of its development. Initially, prevention and mitigation focused more on medical aspects in the health sector. However, recent developments indicate a shift in government intervention that is not only open to medical aspects and the health sector alone but also involves cooperation between sectors, including nongovernmental institutions (KPAN, 2014). This shift is due to the tendency of an increase in the cases of this disease, and the spread observed from the regional aspect is relatively even. In the 2007-2013 period, this case was spread evenly in nearly $80 \%$ of all occurrences and cities in Indonesia (PKMK UGM, 2015)

Subang, West Java is a district with high case rates. It has an infrastructure that enables the mobility of people through the high North Coast Path. Mobility is a component that causes a region to have many people and hasten the spread of HIV/AIDS.). The high level of human mobility and the spread of prostitution in numerous points in the North Coast region make Subang a region with a HIV/AIDS epidemic in West Java (Hugo, 2011)

Until 2018, the number of people living with HIV/AIDS in Subang has reached 1,618 people from various backgrounds and professions. These secondary data are considered an iceberg phenomenon because the amount not reported is estimated to be higher. Classification of people based on age shows an alarming situation. The majority of sufferers are classified in the age group of 20-29 years $(46.54 \%)$, followed by the age group of $30-39$ years $(28.12 \%)$. The sufferers who are categorized as children under 5 years $(2.36 \%)$ 
generally contract the virus while in the womb. This concern is related not only to health problems but also to a lost generation threat.

Subang Regency Government responded to this problem by enacting Subang District Regulation Number 5 of 2013 concerning HIV/AIDS Prevention and Control in Subang District. One agendum is to develop partnerships and collaborations between government and non-government institutions. Then, the HIV/AIDS Prevention and Control Program Design was prepared by the Health Office. In the design, HIV/AIDS prevention and control efforts were emphasized to involve government and non-government institutions in the form of collaboration. The present study aims to (1) explore the practice of HIV/AIDS prevention and control in Subang District, West Java and (2) to model collaborative methods for HIV/AIDS prevention and control in Subang, West Java.

\section{Method}

The practice of collaboration basically refers to two things, that is, the limited resources owned by the government and the desire to solve problems and realize common goals in certain fields. Through collaboration, benefits will be gained by utilizing and developing shared potential.

Collaboration between government and non-government organizations is a new chapter in public administration; this chapter leads to governance models (McNabb, 2009). Gajda and Koliba (2009), stated that collaboration is a form of relationship arrangement between organizations which are involved in a collective work. Various terminologies arise from the term, collaboration which refers to the existence of a network between organizations, including joint ventures, consolidations, networks, partnerships, coalitions, collaboratives, alliances, consortiums, associations, conglomerates, councils, task forces and groups.

Thomson et al. (2007), define collaboration as a process in which autonomous and semi-autonomous actors interact through formal and informal negotiations, develop rules and structures that will regulate the relationship between them and solve problems that they faced together. In this interaction, a process of sharing values and mutual benefits occurs.
According to these various definitions, collaboration can be stated as a joint effort that is multidimensional. Firstly, two or more actors who do not constantly have full autonomy are involved. Secondly, the interactions are performed formally and informally through negotiations between participants. Thirdly, the form of cooperation that exists in a network of work occurs in a relationship structure that becomes a vehicle for them to solve common problems. Finally, in collaboration, a process of sharing values and benefits together is realised. These ideas are consistent with the opinion of Gray (1989), who illustrates that collaboration is a thinking process where the parties involved find a shared solution to the differences and limitations of their views on the solutions that can be implemented.

Various factors of collaboration success are available. Thomson et al. (2007), Vangen and Huxham (2007) and Huxham and Vangen (2009) offer a theoretical framework for determining and exploring the success of collaboration through the following dimensions: governance, administration, organizational autonomy, mutuality, norms and leadership.

Governance is related to involving participants in decision-making, rules of behavior, relations that will occur and the choice of solutions to solve problems collectively. In this stage, the steps to be taken, the type of information required and the costs and benefits to be distributed are determined.

Administration focuses on institutional aspects and implementation and practical management that leads to the objectives to be achieved.

Organizational autonomy refers to the two aspects faced by organizations involved in collaboration. These aspects are maintaining initial identity and achieving organizational goals whilst sharing values with other organizations. In this context, organizational autonomy must 'succumb' to long-term interests by sharing authority with other organizations.

Mutuality indicates that organizations that collaborate must benefit from the dependence that occurs on the dynamics of interest in the group.

Norms refer to the principle of 
reciprocity and mutual trust. In collaboration, the participation of organizations to be involved in achieving common goals shows a mentality of shared feelings and obligations on the basis of the principle of reciprocity.

Leadership, in the collaboration setting, is the ability to influence the entire participant organization, not just individuals or organizations.

This study used a qualitative approach in the form of exploratory studies in collaborative HIV/AIDS prevention and control efforts in Subang Regency. Primary data were collected through in-depth interviews and nonparticipatory observations. In-depth interviews were conducted with three groups of informants as follows: Firstly, organizational bureaucrats in the regional apparatus have the main tasks and functions that directly or indirectly over HIV/ AIDS prevention and control efforts. Secondly, activists from non-governmental organizations are concerned about HIV/AIDS prevention and control efforts as representations of nongovernmental institutions. Finally, people with HIV/AIDS are the target group of HIV/ AIDS prevention and control policies through collaboration.

Risk groups were observed, whilst secondary data were collected through documentation studies. To test the validity of the data, an examination was performed by comparing each datum and information obtained from the three methods of data collection. To overcome informants' bias, efforts were exerted to maintain the validity of research data by applying the principles of triangulation.

The process of data analysis was conducted on three concurrent activities, namely, data reduction, data display and conclusion writing. Data reduction occurred simultaneously with the stage of data collection in the form of reviewing interview transcripts, observation notes and documents and making notes on the data. Display data are discussion steps on a narrative text which ends writing conclusions.

\section{Results and Discussion}

HIV/AIDS prevention and control efforts in Subang Regency are 1 of the 11 activities in the Disease Prevention and Control Program. Thus, the Regional Regulation No
5 of 2013 concerning HIV/AIDS prevention and control efforts in Subang Regency has been implemented. The main efforts in the form of prevention, mitigation and protection are executed by implementing agencies whose existence demonstrates the characteristics of governance.

Facilities to support this policy have been provided as follows: hospitals for Care, Support, Treatment referrals and Prevention of Motherto-Child Transmission of HIV referrals; 3 units of Centre of Public Health with comprehensive services; 12 satellite health centers; 5 Centre of Public Health units with harm reduction services; 1 Centre of Public Health unit with the Methadone Maintenance Therapy Service (PTRM) service and 1 Centre of Public Health unit with a service unit as a Reporting Obligatory Recipient Agency.

\section{Governance}

The involvement of actors in the collaboration network, that is, government and non-government organizations, departs from a collective agreement which began in the phase of general policy formulation and structure design in the Regional Regulations. However, the formulation of the general policies is dominated by regional government institutions, especially the Health Office. The preparation of Regional Regulation No. 5 of 2013 is fully taken by the legislative and executive institutions, without public hearings or by involving other actors outside the government.

Furthermore, the nature of these regional regulations binds all stakeholders to realize and becomes the main driving factor for compliance with the regional device organizations in implementing this policy. This role is inherent in their main tasks and functions, whereas the involvement of non-government organizations in collaboration is implemented on the supporting aspect.

Collaborative efforts are certainly necessary if they refer to the complexity of problems that cannot be solved by a single unit of government organization or even by various governments, thus requiring the involvement of other parties outside the government. A suitable work pattern is the multiagency of actors who have a common interest in solving the problem (Thomson et al., 2007; Haynes, 2003) 
However, the results of the study show that the Subang District Government still dominates the policy process and does not open the involvement of actors outside the government to solve common problems. McNabb (2009), emphasized that collaboration with informal ties is a driving factor in the public sector to implement changes to respond to environmental changes

The description above shows the phenomenon of weak bonds between participants woven through legislation. Therefore, the involvement of participants who have diverse backgrounds, visions and strengths of resources must be encouraged. Formal legal instruments have not become a foothold in establishing the convergence of actors in this collaboration. This case is also evidence that commitment among actors remains weak. Furthermore, numerous actors, especially collaborative regional government organizations, tend to simply 'carry out of obligations' to the mandate of regulation not to solve problems.

\section{Administration}

The administration dimension is related to using formal communication formats among participants, understanding of roles and responsibilities, organizing tasks and supervising participating organizations. The research findings show that dimensions are the bases and means for participants to achieve common goals, although self-administration is ignored in some cases (Thomson and Perry, 2006).

In this collaboration, the participants apply a decentralized structure, where the organization of origin delegates authority to apparatus and activists to make technical decisions, despite interests of the original organization that they maintain in certain cases. Communication activities as a feature of administrative processes become an important part and follow the structure and authority. However, in practice, communication between participants does not rely heavily on formal communication channels. This aspect is prominent when overcoming technical problems in the field where the participants perceive the absence of subordinate positions.

Collaborative activities in the context of administration are generally divided into two parts, namely, medical and non-medical aspects. In general, these medical and non- medical roles represent institutional technical functions where the role of the participants is dynamic in non-medical activities. This condition is due to the fields of activity are broad and require further intensive interactions in addition to the considerable number of participants involved. This situation is different from the role and authority of the actors who are focused on medical activities. The scope of activities is narrower but more detailed in medical activities than in non-medical activities. Moreover, in the former, the perpetrators are relatively limited, and the technical activities are relatively 'closed.

Institutional relationships between participants in this collaboration are characterized by decentralization among participants. However, a structure which requires a central position for coordination, communication, information flow regulation and efforts remains necessary. In addition, resource management can protect participants who hold mutual agreement through social coordination.

Integration of administrative capacities is pursued through coordination and utilization of elements inherent in the hierarchy and social capacity, as stated by Thomson and Ferry (2006); this idea essentially builds institutional relationships between participants. However, given abundant resources, the Health Office remains the dominant actor. In fact, Bryson et al. (2006), opine that configuring the collaborative structure that runs dynamically is tied to the collaboration strategic goals that are woven.

Organizational Autonomy

During the collaboration, all participants from government and non-government institutions maintain their independence, at least from the aspect of their institutional identity. The strength of the interests of every participant can be observed from the strength of the identity and resources possessed by the participants. In this collaboration, the participant who has the strongest identity and interests is the Health Office because this institution has excess resources. Nevertheless, in various activities in the field, the Health Office still requires the presence of other 
institutions, that is, other governmental and non-governmental organizations.

This exchange of information generally occurs without obstacles. For participants from the government, especially the Health Office, information about the sites of People with HIV/ AIDS (PWHA) and their conditions from the participants of non-government institutions is crucial because these non-governmental organizations have considerable time in assisting PWHA. Moreover, for participants from nongovernmental institutions, information from work partners of government institutions is considered important for medical follow-up on the assistance efforts they made to PWHA.

Although, in some cases, the dynamics of dissent and concepts are observed among participants, and the attachment of participants to one another within certain limits remains intertwined. The technical involvement in collaboration is performed without overlapping of activities among the participants. In this collaboration interaction, the participants are faced with the condition of the identity and integrity of the parent organization vis-a-vis identity and collective integrity. Thomson and Perry (2006) refer to this condition as selfinterest versus collective interest, where the identity of the organization origin is at stake. In the collaboration on HIV/AIDS prevention and control efforts in Subang Regency, the output of the conflict between self-interest versus collective interest depends on the resources possessed by the participants.

Participants who have limited resources currently place themselves to disregard the interests of the organization where they come from and priorities collective interests in collaboration, whereas participants who have excess resources become the leading sector for other participants. Thus far, the participants who have different interests have aimed to maintain a balance when faced with the interests of other participants who frequently act in the name of collective interests.

According to Helmke and Levitsky (2004), the model of interaction between participants in this collaboration is included in complementary typologies; in these typologies, filling the gap occurs among the participants when a participant suffers from a shortage of resources or is filled by excess resources owned by other participants, regardless of the original identity of the organization and characteristics of participant partners. Efforts taken to maintain the balance of interests by exploring the common goals of this collaboration are efforts to redesign the organizational structure; the application of the structure is designed for flexible interaction, as mentioned by Beyerlein et al. (2003). Through this balance of interests, this collaboration method can be avoided through collaborative inertia, which is a condition in which a partnership in the form of collaboration has difficulty making changes that refer to the dynamics of the external environment (Huxham and Vangen, 2007).

Moreover, interdependence among participants is relatively strong, although it depends on the character of the activities performed by the participants. Weak interdependence is observed in medical activities which are dominated by the Health Office and its medical service units. By contrast, the level of tendency to prioritize the original organization is quite high, where the original identity of the organization becomes visible. However, nearly all participants acknowledge the benefits of this collaboration.

\section{Mutuality}

In collaborating, participants who have identities, resource capabilities, structures and forms of accountability interact dynamically. This interaction also occurs between individual and collective organizations in collaboration with their ever-changing environment. In conducting this interaction, all participants do not only constantly reach a consensus but also conflicts caused by differences in identity and availability of resources. The differences in institutional status, resource capacity and work methods possessed by participants have implications for emerging strong and weak participants who influence each other when interacting.

The process of public health Office is used as a reference by other participants. The strong influence of the Health Office is also felt by non-government institutions because the Health Office's work programs, including dissemination and assistance, frequently leads to medical treatment whose resources 
are only owned by the Health Office and its service unit network. Another interesting thing is that the aspect of communication between participants is the most important element in maintaining togetherness despite the gaps among participants in the ability of resources. Constructive communication which leads to competency transformation among participants occurs in technical activities in the field in the form of horizontal communication with cargo using an all-channel network model. The advantage of using this model is that participants have the freedom for reciprocal interactions without noticing the central figure. All communication networks between participants are unlimited, and each participant is relatively free to interact with various parties or vice versa (Robbins et al., 2018).

Based on field observations, the ways of thinking and the works among the participants who came from government and non-governmental organizations are certainly different. Activists prioritize work outcomes, rather than take or utilize aspects of governance in their activities. The different ways of working between participants from government and non-governmental organizations are feasible because the identity between the two participants is different from one another. According to the theory of government failure, the role of non-governmental institutions initially provides public goods in certain areas where the government is unable to respond to the requirements of certain community groups (Feiock and Andrew, 2006).

In the context of collaboration on HIV and AIDS prevention and control, this role of the relationship between non-government and government institutions tends to shift and form a complementary model, in which this institution establishes partnerships as equal partners with government institutions (Feiock and Andrew, 2006), In the relations between government and non-government institutions, three typologies of relations are available. These typologies are presented as follows: (1) supplementary, where the role of non-governmental institutions arises when a 'vacant role' of the government in providing public goods influence public disappointment; (2) complementary, where non- governmental institutions and the government collaborate to provide public goods; and (3) adversarial, where non-government institutions encourage 'from outside' to enable the government to provide certain public goods (Feiock and Andrew, 2006).

However, the difference between the participants' roles based on institutional status can be reduced because the participants in this collaboration from government and nongovernmental institutions have a 'burden' of interdependence with one another. According to Thomson et al. (2007; Thomson and Perry, 2006), the sense of togetherness in collaboration is rooted in the dependence between actors; in the collaboration process, these participants share interests based on homogeneity and mutual respect for each other.

Another difference that appears in the interaction of participants is their perspective of professionalism in performing their functions. Actors from the elements of government organizations generally tend to show their status as a state civil apparatus with all their attributes. These actors are different from the activists who are members of non-government institutions. In general, they tend to ignore formalities in performing their activities, although they still explain the identity of their original organization when communicating with the target group. These activists tend to lead to voluntarism that is not marked by formality. However, given the scale of small organizations with limited resources, they have encouraged them to join collaborative networks and reduce their autonomous content (Jang, Feiock and Saitgalina, 2016). The existence of these differences within certain limits creates conflict in the context of quality; therefore, the main problem lies in power imbalance (Anshell and Gash, 2007).

\section{Norms}

Complex problems and diverse institutional backgrounds and resource capabilities impact the dynamics of aspects of trust and reciprocity. At the level of policy formulation, the dynamics are invisible. The participants in this collaboration acknowledge that mutual trust between them is an important aspect of establishing a network.

In general, statements that arise from 
government actors tend to be macro and normative. Furthermore, the actors state that preventing HIV/AIDS is not solely the responsibility of the government but a joint responsibility. Such expressions of the legislature, regional heads and the heads of OPD on various occasions and the media, including mass media.

In fact, the imbalance in ownership of these resources results in distrust of the ability of co-workers to impact the acceptance of all decisions. Trust in these participants is finally formed, as marked by the continued implementation of a collaborative network. Resource limitations among numerous participants are finally accepted by other participants who had excess resources as an item that is given and unavoidable. The distrust of the existence of weaknesses in co-workers is also accepted as an unavoidable entity and still maintains the collaboration.

In field activities, these participants continue to collaborate with the data in which, in certain activities, participants with the power of excess resources are the dominant ones. This phenomenon can be observed in the role of the Health Office which is dominant in the aspect of care. By contrast, in the dissemination activities for certain vulnerable groups that are difficult to access, such as homosexual groups, activists from non-governmental institutions dominate the activities. The discussion on the aspects of norms is closely related to the dimension of mutuality which emerges from the interdependence between actors (Thomson et al., 2007; Thomson and Perry, 2006).

This pattern of dependence and exchange of resources subsequently lead to mutual recognition and acceptance as work partners, and trust between participants is built. The important thing in this dimension of norms is that the dynamics for forming mutual trust and reciprocity in the exchange of resources occur extensively and take a repetitive and continuous process (Thomson et al., 2007). In particular, in this collaboration, norm dimensions are formed through institutionalization, thereby indicating the application of rules and procedures that regulate interactions between actors (Helmke and Levitsky, 2004). The level of trust in fellow partners is high because of interdependence.
This high trust among participants slightly suppresses the collaborative inertia.

\section{Leadership}

The meaning of the dimension of leadership in collaboration is different from the terminology similar to a single organization but approaches social leadership. Subordination of the leadership dimension to collaborative practice is the entirety of the participatory collaboration organization, not just individuals or organizations (Vangen and Huxham, 2003).

Leadership in HIV/AIDS prevention is divided into two domains, namely, political and managerial. In the political domain, collaborative efforts among stakeholders are not very prominent. Political actors from the executive and the legislature show concern for HIV/AIDS prevention and control at the stage of policy formulation in the form of Subang District Regulation No. 5 of 2013. This regulation is an initiative of the legislature. The formulation went smoothly without debate. However, in the formulation, no discussion transpired among relevant stakeholders.

In the managerial domain, the highest leadership aspect is the Regent of Subang, who is an ex officio of the KPA District Head. As the chairperson of the KPA ex-official, the Regent of Subang does not have much involvement in operational technical activities of prevention and mitigation. His role is very tiny, but his power is great. Therefore, this role is not wellimplemented, as reflected in the very small budget allocation for HIV/AIDS prevention and control.

The position of a regional head occupies a quadrant in the category of high importance and power position and has the freedom to formulate and implement a program. In the HIV/AIDS prevention in Subang Regency, this role is only formally legal in nature and has no real impact among others, as indicated by inadequate budget support.

In the managerial context, collaborative activities are technical in nature. The situation is dynamic because it is faced directly with real problems in the field. This aspect of leadership at the technical level is prominent in controlling participants in teamwork because leadership in individual organizations that oversee the work unit is felt differently when performed in 
numerous participant organizations outside the work unit environment. In fact, collaboration leaders, that is, political and managerial, are required to understand that the efforts influence not only individuals but also other organizations that have no hierarchical relationship, as found in individual organizations.

In the present study, two leadership groups, namely, managerial and facilitative, emerged. The leadership that has been conducted is managerial leadership. Although the Regional Head has high interests and power, this position is not comparable to the complexity of the problem. Managerial leadership does not work effectively, thereby encouraging different participants because it remains a single organization.

Collaborative HIV/AIDS Prevention and Control Model in Subang Regency

Collaborative activities in a model, although understood as an iterative process and are in the format of a cycle, are part of a system process that has elements of input, transformation and output. This part has implications for the emergence of integration in the manifested elements of interpersonal relations, psychological attachment among participants, mutual understanding with informal frames and commitment to share in a network, thus forming a synergic process. In this designed model, a series of activities is depicted, with the main focus on collaboration, which illustrates the problem, the problemsolving process and the expected results of the process. Thus, models that are designed are practically oriented to problem-solving.

In general, the collaborative prevention and control model of HIV/AIDS in Subang Regency is represented in the form of an activity flow which consists of elements, namely, collaborative motives, initial conditions, facilitative leadership, collaborative processes, tangible and intangible outputs and outcomes.

Collaborative activity in the image is the dynamic interaction of the participants in the six dimensions that are presented in a system model. The input to this system consists of the motives of the participants and the initial conditions before the collaboration begins. The main motive for collaboration is the complexity of the problem and scarcity of resources and cannot be solved by one work unit individually. The implication is that interdependence occurs among the participants. Bryson, Crosby and Stone (2015), refer to the motivations of actors to become participants as general antecedent conditions.

In the initial conditions, the collaborative

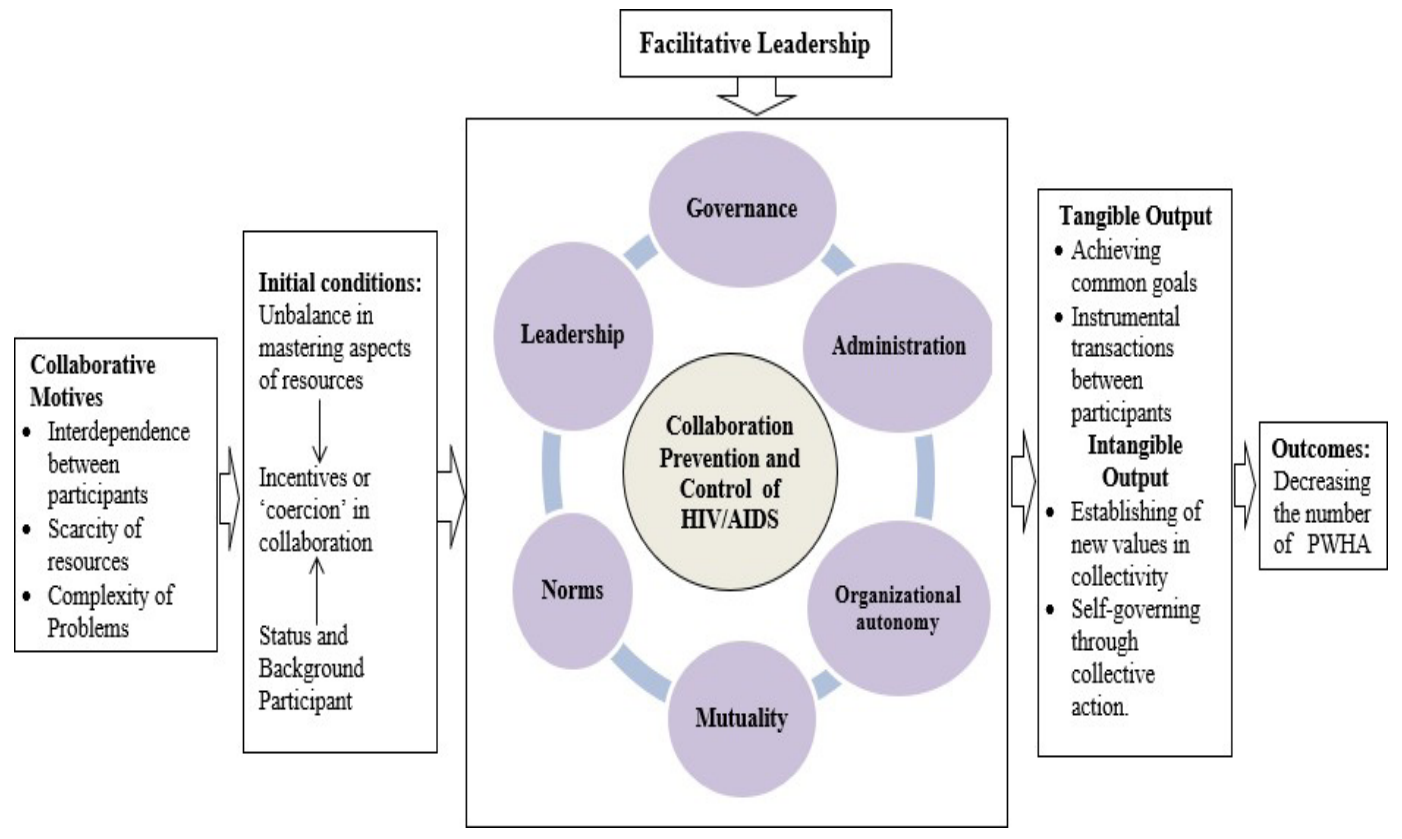

Source: Adapted from Thomson and Perry (2006); Bryson, Crosby and Stone (2015)

Figure 1 HIV/AIDS Prevention and Mitigation Model 
design is performed by the participants with the mandate of each institution. Two difficulties are encountered at this stage, that is, the imbalance of capacity and capacity of the resources owned and the diverse status, background and interests of each participant (Ansell and Gash, 2007). At this stage, the participants who bear the burden of other partners have weaknesses in terms of power and resources. This condition is called disincentive. The participants are forced to perform their roles while blocking their resources. This form of disincentive is experienced by participants who have large power and resources. However, for the sake of mutual commitment, resources must be allocated to 'close' the lack of other participants.

Conversely, certain participants benefit from obtaining transfers of power and resources from partners who have a surplus. This condition is called an incentive given the freedom to perform its functions and the support of other participants. This incentive is obtained by participants who have high interests but are low in resources.

In the transformation phase, the effort taken is to form a collaboration network that involves government and non-government institutions with various aspects of differences (O'Leary and Vij, 2012). At this stage, the participants interact to form joint actions to achieve mutual benefits and reduce the obstacles experienced. In this process, collaboration activities are cyclical and iterative over a long period.

The research findings show that the transformation process is strongly influenced by facilitative leadership in the regional heads. In collaboration, regional heads are not directly involved. However, with their position as holders of power, they have high interests and power in mobilizing resources at the stage of program formulation, monitoring and evaluation.

This role can be observed in the form of regional regulations, regional medium-term development plans and regional government work plans. The facilitative role of the regional heads as stakeholders is a new finding in this study. Previous studies have not discussed the role of facilitative leadership in applying collaboration in the practice of regional autonomy. At the output stage, the two forms of collaboration are tangible and intangible outputs (Bryson, Crosby and Stone, 2015). A tangible output refers to achieving goals with participants in a collaboration; that is, a network that leads to efforts for reducing the number of people living with HIV/AIDS to a zero case must be implemented as outcomes of the model. In addition, instrumental transactions between participants in social relations exhibit an effort to balance resources among participants through the transfer of capacity to avoid collaborative inertia. An intangible output is realized in the context of forming new values in developing resource capacity and self-governing through collective action. The planting of new values in solving public problems by producing public goods no longer places the government as the dominant actor but involves non-governmental elements and decision-making based on togetherness and equality.

\section{Conclusion}

Research on collaborative models theoretically points to the dimensions of governance, administration, organizational autonomy, mutuality, norms and leadership that occur in a cyclical and iterative process. Practically, this model is obtained in linear processes and causality which describes a system that leads to forming new values.

Autonomous regional heads become an important element with facilitative leadership roles as a typical Indonesian phenomenon that complements the collaboration model. Facilitative leadership includes the ability to mobilize various capacities across organizations that are considered participants and forming a work environment which accommodates various organizations with different backgrounds, interests and resource capabilities.

\section{Acknowledgment}

Thank to Subang University for funding support in this study and Padjadjaran University for the discretion time given during this research. Hopefully the results of this study will be a source of policy making on HIV-AIDS prevention.

\section{References}

Aggleton, P., Bhana, D., Clarke, D.J., Crewe, M., 
Race, K., \& Yankah, E., 2018. HIV education: Reflections on the Past, Priorities for the Future. AIDS Education and Prevention, 30(3), pp.254-266.

Agranoff, R., 2012. Collaborating to Manage: A Primer for The Public Sector. Washington DC:Georgetown University Press.

Anonymous., 2015. Policy Brief: Strategies to Strengthen the Involvement of Community and Religious Leaders in Supporting Promotion of the Prevention of HIV Transmission through Sexual Transmission. Center for Health Policy and Management, Faculty of Medicine, Gadjah Mada University (PKMK UGM). ., 2014 Two Decades of AIDS Prevention Commission, National AIDS Commission (KPAN), March 2014.

Ansell, C., \& Alishin, G., 2007. Collaborative Governance in Theory and Practice. The Journal of Public Administration Research and Theory. Oxford University Press. 18, pp. 543- 571.

Beyerlein, M.M., Freedman, S., Mc Gee, C., \& Morgan, L., 2003. The Ten Principles of Collaborative Organizations. Journal of Organizational Excellence. Wiley Periodical Inc, Spring, 22(2), pp.51-63.

Bryson., John, M., Barbara, C., Crosby., \& Stone, M.M., 2006. The Design and Implementation of Cross-Sector Collaboration: Propositions from Literature. Public Administration Review, 66, pp.44-55.

Bryson., John, M., Barbara, C., Crosby., \& Stone, M.M., 2015. Designing and Implementing Cross-Sector Collaboration: Needed and Challenging. Public Administration Review, 75(5), pp.1-15.

Demartoto, A., 2015. Effectiveness of Collaborative Governance in Sustainable Comprehensive Services to Overcome HIV / AIDS. Kesmas: National Public Health Journal, 9(4), pp.382389.

Feiock., Richard, C., \& Simon, A.A., 2006. Introduction: Understanding the Relationships Between Nonprofit Organizations and Local Governments. International Journal of Public Administration, 29, pp.759 - 767.

Gajda, R., \& Christopher, K., 2009 Evaluating the Imperative of Intraorganizational Collaboration: A School Improvement
Perspective. American Journal of Evaluation, 28(1).

Gray, B., \& Wood. D., 1991. Collaborative Alliance: Moving from Practice to Theory. Journal of Applied Behavioral Science, 27(2), pp.3-22.

Haynes, P., 2015. Managing Complexity in The Public Service. Routledge, New York.

Hugo, G., 2011. Population Mobility and HIV / AIDS in Indonesia. UNAIDS Indonesia: Jakarta.

Helmke, G., \& Levitsky, S., 2004. Informal Institutions and Comparative Politics: A Research Agenda. Perspectives on Politics, 2(4), pp.725-740.

Huxham, C., \& Vangen, S., 2007. Doing Things Collaboratively: Realizing the Advantage or Succumbing to Inertia. Collaborative Governance: A New Era of Public Policy in Australia?. Australia National University E Press: Canberra.

Jang, F., \& Saitgalina., 2016. Institutional Collective Action Issues in Nonprofit Self- Organized Collaboration. Administration \& Society, 48(2), pp.163-189.

McNabb, D.E., 2009. The New Face of Government: How Public Managers Are Forging a New Approach to Government. CRC Press: Boca Raton.

O’Leary, R., \& Nidhi, V., 2012. Collaborative Public Management: Where Have We Been and Where Are We Going?. The American Review of Public Administration, 42(5), pp.507- 522.

Robbins, S.P., Judge, T.A., \& Breward, K.E., 2018. Essentials of Organizational Behaviour. Canada Edition, Pearson Canada Inc. Ontario.

Thomson, A.M., \& James, L.P., 2006. Collaboration Process: Inside the Black Box. Public Administration Review. Special Issue December 2006, pp.20-32.

Thomson, A.M., James, L.P., \& Miller, T.K., 2007. Conceptualizing and Measuring Collaboration. The Journal of Public Administration Research and Theory, 19(1), pp.23-56.

Vangen, S., \& Huxham, C., 2010. Introducing the Theory of Collaboration Advantage., in Stephen P. Osborne., 2010. The New Public Governance: Critical Perspectives and Future Direction, 1st Edition, Routledge New York. 